\title{
Clinical Presentation and Management of Hydatidiform Mole in a Peripheral Tertiary Hospital
}

\author{
JAGLUL HAIDER KHAN ${ }^{1}$, JANNATUL FERDOUS ${ }^{2}$, SAMIYAALAM ${ }^{3}$
}

\begin{abstract}
:
This study was conducted in Faridpur Medical College Hospital, Faridpur, from January 2008 to December 2008 among fifty patients, diagnosed as a case of molar pregnancy. Incidenc of molar pregnancy was 8.27 per thousand pregnancy. Sixty percent of the patients were multiparous and eighty percent of low socio economic status . B positive blood group was prevalent (36\%) in this study. Sixty percent (60\%) of the patients presented with amenorrhoea and abnormal vaginal bleeding.. Most of the patients (72\%) were treated with suction evacuation and curettage. Of them hemorrhage was the most common immediate complication (80\%). Complication like shock and perforation during evacuation was $14 \%$ and $4 \%$ respectively. Three patient (6\%) developed Persistent Gestational Trophoblastic Disease(GTD) and one (2\%) patient developed choriocarcinoma with lung metastasis and died. Thirty two (64\%) patients attended for regular follow up but ten patients (20\%) had attended irregularly and eight patients (16\%) had dropped out. This study shows that follow up for molar pregnancy cases is not satisfactory in a district medical college hospital.Further improvement can be done by increasing awareness of the patients.
\end{abstract}

\section{Aims and Objectives:}

1. To analyze the pattern of clinical presentation of molar pregnancy in a peripheral tertiary referral hospital.

2. To evaluate pattern of complications presented with and the complications that arises during and after treatment.

3. To evaluate the management including follow up in a peripheral tertiary hospital.

Introduction:

Gestational trophoblastic neoplasia is a pregnancy related disorder that has been applied to describe the different pathological appearance of trophoblastic tissue. It. includes hydatidiform mole, invasive mole, placental site trophoblastic tumors and choriocarcinoma. Among them hydatidiform mole is the most common. It develops from the placental tissue during early pregnancy in which the embryo fails to develop normally.. Microscopically mole may be identified by three classic findings ${ }^{1} 1$. Edema of villous 2. Avascular villi. 3. Nest of proliferating syncytotrophoblast and cytotrophoblast element surrounding villi.
In about half of all cases of choriocarcinoma and 10 to $15 \%$ of invasive mole the antecedent pregnancy is hydatidiform mole. Regardless the method of termination close follow up with serial beta HCG titer is essential for every patient because the incident of malignant disease commonly thought to be $20-30 \%$ and the cure rate of properly treated metastatic gestational trphoblastic neoplasia is approximately $90 \%{ }^{1}$. This trophoblastic disease has got a wide range of complications. It may be persistent resulting metastatic or nonmetastatic malignant disease and may recur in subsequent pregnancy.

Molar pregnancy occur most frequently in South East Asia like Malaysia, Singapore, Hong Kong, Indonesia, Philippines and China $^{2}$. Incidence in Philippines is 1 in 80 ,in India is 1 in $400^{3}$. The exact etiology of the disease is yet unknown, but it appears to be related to the ovular defect as it some times affects one ovum of a twin pregnancy. There is an increased risk in teenagers and woman over 35 years. The rate rises to 10 fold after the age of 40 years $^{1}$. Patients with higher parity are at higher risk in under developed countries ${ }^{4}$. No parity effect was found in two studies

1. Assistant professor, Obstetric \& Gynaecology, Dhaka Medical College

2. Associate professor, Gynaecological Oncology, BSMMU

3. Assistant register, Obstetric \& Gynaecology, $\mathrm{FMCH}$ 
done by Jonathan Buckley $1984^{5}$. More than $95 \%$ of complete mole are female (46xx). The partial mole is usually triploid. The prevalence appears to vary with race and ethnic origin. More common in certain racial groups. Blood group A woman mating with group A man are at least risk \& risk is 10 fold greater if mate with group $O$ man. Women with group $A B$ have relatively poor prognosis ${ }^{3}$. It occurs especially in rice eater and in those whose diets are deficient in protein, folic acid and carotene. The occurrence of a trophoblastic tumor can be regarded as the result of a breakdown in what must be a complicated host invader balance. There are also reports of matching leucocytic HLA types between the woman and her partner. The lack of ability to control trophoblastic activity has two possible basis an inherent or immunological one and one which results from malnutrition and debility.Gestational trophoblastic tissue may suppress the maternal immune response via such factors as interleukins and tumor necrosis factor.Rise of gamma globulin level in absence of hepatic disease.Increase association of $A B O$ blood group which possesses an $A B O$ antigen ${ }^{2}$.

The symptom which most often calls attention to the abnormality is recurrent uterine bleeding. Nausea, vomiting have been reported in $14-32 \%$ of patients of hydatidiform mole and may be confused with nausea and vomiting of early pregnancy. In over $80 \%$ of cases the first evidence of hydatidiform mole is the passage of vesicular tissue, bleeding and brown discharge.

The uterus is too large for the period of amenhorrea. is present in only $50 \%$ of cases. Sometimes the uterus is smaller than normal, especially if the mole dies. Enlargement of both ovaries seen in 25-30\% of molar pregnancy. Suction evacuation and curettage is the preferred method of choice regardless of uterine size. When a large hydatidiform mole ( $>12 \mathrm{wks}$ size) is evacuated by suction curettage a laparatomy set up should be readily available as hysterotomy, hysterectomy, or bilateral hypogastric artery ligation may be necessary if perforation or hemorrhage occur ${ }^{1}$. .In all cases even if the mole has been removed by hysterectomy regular observation of patient is essential to detect the first sign of remaining or reawakening chorionic activity ${ }^{3}$. Follow up is done with serial beta HCG estimation, gynecological examination \& Chest radiography. Approximately $70 \%$ patients develop a normal beta HCG within 8 weeks post evacuation. Another $15 \%$ demonstrate continuous decline in titer and ultimately achieve normal titer without treatment . Rest 15\% who have elevated titer at 8 weeks postevaquation demonstrates rising titer or platue. Nearly half of these patients will have histological evidence of invasive mole and the other half will have choriocarcinoma.

\section{Materials and Methods:}

It was a prospective type of descriptive cross sectional study . conducted in the department of obstetrics and gynecology of Faridpur Medical College hospital from January 2008 to December 2008 . Fifty consecutive patients who were admitted in the Obstetric and Gynae department of Faridpur Medical College Hospital and diagnosed as Hydatidiform mole had been taken as the study population. Diagnosis was made by ultrasonographic findings \& serum BhcG assay . Histopathology was done in all the patients.

Study size (n) - $\quad Z^{2} \mathrm{pq} / d^{2}$, Here, $-\mathrm{Z}=1.96, \quad \mathrm{P}$ $=50, q=50, d=10 \%$ of $p-5 \%$ (Here actual prevalence is not known)

$n=1.96^{\wedge} 1.96^{\wedge} 50^{\wedge} 50 / 5^{\wedge} 5=384$

Therefore the required sample size $n=384$, but due to the reduced patient attendant it was not possible to collect required number of sample. After fulfillment of eligibility criteria 50 cases were collected during the study period. Sampling technique was purpusive consecutive sampling.

\section{Measurement of out Come Variable}

\section{Following outcome variables were studied}

A. Demographic variables- Age, Parity, Socio economic Condition, Blood group,Obstetric history \& previous history of molar pregnancy .

B. Clinical variables- Presentation at admission like amenorrhoea, pervaginal bleeding,pervaginal passage of vesicles, lower abdominal pain \& exaggerated sign symptoms of pregnancy, and gestational period at admission. Ultrasonography \& Serum BhcG assay were the main diagnostic tool in this study.

C. Other variables were mode of treatment, complications,followup and prognosis of the patients

Data were collected in a preformed questionnaire and from direct clinical evidence. All datas are presented in tables. After collection of required information data were checked and processed manually, researched, 
analysed and edited by computer and simple statistical calculation were done by using percentage. Ethical clearance was taken from ethical committee of Faridpur Medical college hospital.

\section{Results:}

During the study period total 5625 pregnant patients and 350 patients with abortion and 75 ectopic pregnancies were admitted in this hospital .Among them 50 were suffering from Gestational trophoblastic disease. So incidence of Gestational trophoblastic disease was 8.27 per thousand pregnancies. Eighty percent(40) of the patient were in low socioeconomic group and 16\%(8) from middle and only 4\% from upper class. Thirty six percent(18) of the patients blood group were $B+v e, 30 \%$ O+ve, $26 \%$ A+ve, and $8 \% A B+v e$. None of them were negative blood group. In the study population $60 \%$ of patient presented with amenorrhea and per vaginal bleeding . Twenty percent(10) presented in addition with passage of vesicles, $4 \%(2)$ presented with amenorrhea with exaggerated sign symptoms of pregnancy and 4\%(2) had no symptoms other than amenorrhea (table-1). Among 50 patients $72 \%$ came before 16 weeks of gestation at the time of presentation and no patients after 24 weeks of gestation (table-2). In this study $72 \%$ patients were diagnosed with clinical suspicion and confirmed by USG. In $4 \%$ cases diagnosis was accidental during routine USG. Histopathology was done in all patients. Out of 50 patients $80 \%$ were complicated with hemorrhage, $8 \%$ were complicated with shock $4 \%$ were complicated with sepsis and $8 \%$ presented with no complications (table-3). Thirty patients (60\%) were between 20-29 years of age and only $4(8 \%)$ were above 40 years. Fourty percent(20) of patients were nulliparous and $40 \%$ were of low parity and $20 \%$ were grand multipara

Table-I

Clinical presentation of the cases $(N=50)$

\begin{tabular}{lcc}
\hline Presenting symptoms & $\begin{array}{c}\text { Number of } \\
\text { patients }\end{array}$ & Percentage (\%) \\
\hline $\begin{array}{l}\text { Amenorrhea with vaginal } \\
\text { bleeding }\end{array}$ & 30 & 60 \\
$\begin{array}{l}\text { Amenorrhoea with vaginal } \\
\text { bleeding \& passage of vesicles }\end{array}$ & 8 & 16 \\
$\begin{array}{l}\text { Amenorrhea with lower } \\
\text { abdominal pain }\end{array}$ & 8 & 16 \\
$\begin{array}{l}\text { Amenorrhea with } \\
\text { exaggerated sign } \\
\text { symptoms of pregnancy }\end{array}$ & 2 & 4 \\
$\begin{array}{l}\text { Amenorrhea was the only } \\
\text { symptom diagnosed during } \\
\text { routine USG }\end{array}$ & 2 & \\
\hline
\end{tabular}

Table-II

gestational period at the time of presentation $(N=50)$

\begin{tabular}{lcc}
\hline $\begin{array}{l}\text { Period of amenorrhea } \\
\text { at the time of } \\
\text { presentation }\end{array}$ & $\begin{array}{c}\text { Number of } \\
\text { patients }\end{array}$ & Percentage, (\%) \\
\hline$<12$ weeks & 13 & 26 \\
$12-16$ weeks & 23 & 46 \\
$17-20$ weeks & 10 & 20 \\
$21-24$ weeks & 4 & 8 \\
$>24$ weeks & 0 & 0 \\
\hline
\end{tabular}

Table-III

Immediate complications in study cases $(N=50)$

\begin{tabular}{lcc}
\hline $\begin{array}{l}\text { Immediate } \\
\text { complications }\end{array}$ & $\begin{array}{c}\text { Number of } \\
\text { patients }\end{array}$ & Percentage, (\%) \\
\hline Hemorrhage only & 40 & 80 \\
Hemorrhage and shock & 4 & 8 \\
Sepsis & 2 & 4 \\
Without any complications & 4 & 8 \\
\hline
\end{tabular}

Seventy two percent (36) patients received first line treatment with suction evacuation\& curettage, 12 (24\%) patients were treated by D\&C due to incomplete evacuation earlier and 2 patients needed laparatomy followed by hysterectomy due to uterine perforation (table-4). Among 50 patients $28 \%$ had incomplete evacuation and $14 \%$ developed shock and $4 \%$ had uterine perforation managed by resuscitation by blood transfusion followed by laparatomy and hysterectomy (table -5 ). In this study $64 \%$ of patients appeared for regular follow up for one years. $20 \%$ appeared irregularly and $16 \%$ dropped out.(Table-6).

Table-IV

Surgical treatment of the cases $(N=50)$

\begin{tabular}{lcc}
\hline $\begin{array}{l}\text { Treatment received } \\
\text { by the patients }\end{array}$ & $\begin{array}{c}\text { Number of } \\
\text { patients }\end{array}$ & Percentage, (\%) \\
\hline $\begin{array}{l}\text { Suction evacuation } \\
\text { and curettage }\end{array}$ & 36 & 72 \\
$\begin{array}{l}\text { D\&C } \\
\begin{array}{l}\text { Suction evacuation } \\
\text { followed by total } \\
\text { abdominal hysterectomy }\end{array}\end{array}$ & 2 & 24 \\
\hline
\end{tabular}


Table-V

immediate postoperative complications $(N=50)$

\begin{tabular}{lcc}
\hline Complications & $\begin{array}{c}\text { Number of } \\
\text { patients }\end{array}$ & Percentage, (\%) \\
\hline Incomplete evacuation & 14 & 28 \\
Shock & 7 & 14 \\
Perforation & 2 & 4 \\
\hline
\end{tabular}

Table-VI

Follow up of patients $(\mathrm{N}=50)$

\begin{tabular}{lcc}
\hline Follow up & $\begin{array}{c}\text { Number of } \\
\text { patients }\end{array}$ & Percentage, (\%) \\
\hline Regular follow up & 32 & 64 \\
Irregular follow up & 10 & 20 \\
No follow up & 08 & 16 \\
\hline
\end{tabular}

Among the regular followed up patients 2 (6.25\%) patients develop Persistent Gestational Trophoblastic Disease(GTD) and 30 patients(93.75\%) did not develope any late complications and completely cured. Among the 18 patients who had failed regular follow up one patient (5.5\%) developed Persistent Gestational Trophoblastic Disease(GTD) (table-7). 8 patients received no follow up and one of the dropped out patient later presented with severe anemia and respiratory distress and diagnosed choriocarcinoma and died. So $60 \%$ patients cured completely and one patient died due to severe complication due to failed follow up (table-8).

\section{Discussion:}

In this study the incidence of molar pregnancy was 8.27 per thousand pregnancies that is 1 in 121 pregnancies .Study by Nahar (20005-2006) in FMCH \&BSMMU showed incidence of molar pregnancy to be 1 in 141 pregnancy that is 7.08 per thousand pregnancy6. Another study by Khatoon RA 1993 in $\mathrm{DMCH}$ it was found that the incidence was 1 in 107 pregnancies e.g. 9.3 per thousand ${ }^{7}$. Study by Akhter 1978-1980 at SSMC and Mitford Hospital showed that incidence of molar pregnancy was 1 in 144 delivery that is 6.9 per thousand ${ }^{8}$. Study by Mungan E. 1996 showed much lower incidence 1.84 per thousand pregnancies $^{9}$. Another study in India by Reddy and Rajeswari during 1989-91 showed an incidence of 4.08 per thousand pregnancies ${ }^{10}$. In this study maximum number of patients (60\%) were in 20-29 yrs age group . Study by Nahar (2005-2006) at FMCH \& BSMMU showed that $64 \%$ patients were in $20-29$ yrs age group ${ }^{6}$. A study by Khatoon RA in 1993 at DMCH showed that $63.75 \%$ patients were in $21-30 \mathrm{yrs}$ age group ${ }^{7}$. Another study of 287 patients was done in Pusan, Korea ${ }^{11}$ which showed highest number patients (70\%) were below $30 \mathrm{yrs}$ of age. In a study of 38 cases from the department of Obstetrics and Gynecology, Pennsylvenia Hospital, maximum (60\%) patient was between 20-30 years. Findings of this study are comparable of the previous ovservations .In present series most of the patients $(60 \%)$ were multipara. also a large percentage (40\%) of patients were nulliparous .

The study of 50 cases of GTD at Triput Maternity Hospital India by Reddy and Rajeshwari showed that $70 \%$ patients were of 1-3 parity where as the study of 310 cases by Mungan et al (1996) differ from present study in that multiparty was found to be strongly associated with hydatidiform mole in $60 \%$ cases. So findings of present study were consistent with other study but it differed from the study by Mungan et al (1996) ${ }^{9}$.

In present series most of the patients with molar pregnancy had blood group B (36\%). In the study of Nahar most of the patients with molar pregnancy had blood group A (32\%). The study of Reddy and Rageshwary (1994) showed $52 \%$ of molar pregnancy patients had blood group O. Study by Nahar in FMCH \& BSMMU Hospital (2005-2006) showed abnormal vaginal bleeding and amenorrhea were the commonest (60\%) complaints $^{6}$. According to Gold Stein DP, Berkowitz RS (1994) the most common presenting symptom in patients was bleeding $(97 \%)^{13}$. A study by Curry SL from North Carolina USA of 347 patients $89 \%$ of patients had abnormal bleeding ${ }^{14}$. In this study (Table-1) $60 \%$ patients presented with abnormal vaginal bleeding with amenorrhea,16\% presented in addition with passage of vesicles, $4 \%$ of patients were diagnosed accidentally by USG and had no symptom except amenorrhea.

Out of 50 patients $46 \%$ patients were at 12-16 weeks of gestation at the time of admission (Table-2) which is consistent with the study of Nahar with (40\%) patients with 12-16 weeks of gestation at admission ${ }^{6}$. No patients presented beyond 24 weeks and $26 \%$ patients presented before 12 weeks in this series. In the present study diagnosis was confirmed by USG $72 \%$ and pre evacuation serum beta HCG in (20\%), $4 \%$ was diagnosed by USG without any symptom. Histopathology was done for all patients . 
Most of the patients (80\%) in this series came with hemorrhage as the immediate complication, $8 \%$ presented with shock $4 \%$ presented with no complication, no patient presented with preeclampsia.In Nahar study $80 \%$ presented with hemorrhage as immediate complication,12\% presented with shock, no patients had preeclampsia.A study of 327 patients by curry S.L. from North Carolina showed that $80 \%$ had abnormal uterine bleeding. $12 \%$ developed preeclampsia.So our study correlates with both the studies in that maximum presentation was as hemorrhage as immediate complication, but other severe complication like shock is comparatively low in this series probably because of early presentation \&early intervention than previous which can also explain that some patient also had no complication at diagnosis.

Among the treated patients 14(28\%) patient had incomplete evacuation and treated with D\&C.Seven (14\%) patients developed shock and managed with blood transfusion and other measures. Two (4\%) patient had uterine perforation and had laparatomy followed by hysterectomy (Table-4).Among the three patients (6\%) who developed persistent mole (Table7) had no evidence of metastasis. Two of them were treated with chemotherapy and one was treated with total abdominal hysterectomy. One patient (2\%) who attended no follow up developed choriocarcinoma and presented with severe anemia \& lung metastasis and died. Follow up of the patients were done by clinical examination, serum beta HCG, X-ray chest (where indicated) and USG (where indicated) for a period of 1 year. In this series (Table-6) 32(64\%) patients of GTD attended for regular follow up, 20\% had irregular follow up, $16 \%$ had dropped out . In the study of Nahar Shamsun $70 \%$ patients attended for regular follow up, and 30\% dropped out. In her study no patient had attended irregularly for follow up.

Thirty (60\%) patients were cured by $6-8$ weeks, $6 \%$ developed persistent mole which was evidenced by persistently increasing or pleatu of beta HCG and $2 \%$ developed choriocarcinoma which was evidenced by presence of pulmonary metastasis and increasing or raised level of beta HCG. In comparison to Nahar study (2005-2006) in FMCH and BSMMU that showed $8.55 \%$ patients developed persistent mole and $5.7 \%$ patients developed choriocarcinoma, but cure rate was similar. In Boston 23\% patients developed persistent trophoblastic disease ${ }^{16}$ and in Ankara Turkey (1996)
14.5\% patients were diagnosed as persistent molar disease $^{9}$.

\section{Conclusions:}

Incidence of GTDs in FMCH was 8.27 per thousand pregnancies, more common in multiparous women of low socioeconomic class and in B+ve blood group women. Incidence in nulliparous is also high.Maximum patients presented at 12-16 weeks of gestation with abnormal vaginal bleeding. Seventy two percent patients were treated with suction evacuation and curettage. Hemorrhage was most common complication .During one year of surveillance period $64 \%$ patients attended the follow up protocol regularly, $20 \%$ had irregular follow up and16\% dropped out . The incidence of Persistent Gestational Trophoblastic Disease(GTD) was $6 \%$ and choriocarcinoma was $2 \%$. It seems that attendants for follow up can be raised by proper counseling and raising awareness of the patients. As prognosis of persistent GTD can only be improved by early diagnosis of the cases and by early administration of chemotherapeutic agents, only way to save these women by regular follow up. That is only possible by raising awareness and counseling.

\section{References:}

1. Decherney, Nathan,Current Obstetrics \& Gynecologic Diagnosis \& Treatment, $10^{\text {th }}$ edition,2007,McGraw-Hill, 885-894

2. Dutta D.C. Text book of Obstetrics, $6^{\text {th }}$ edition,2007, Typesetter andPrinter,28-36,385-424

3. Kumer, Malhotra, Jeffcoate's principles of Gynecology, $7^{\text {th }}$ edition,2008,Jaypee Brothers,p161-169.

4. Parazzaini F et al.Risk factors for gestational trophoblastic disease, a separate analysis of complete and partial moles. J Obstel Gynaecol,1991; 78(6);1039-1045

5. Buckley JD. The epidemiology of molar pregnancy and choriocarcinoma. J Clin Obstel Gynaecol 1984; 27(1):153-.156

6. Nahar, Molar pregnancy Analysis of 50 cases in $\mathrm{FMCH} \& \mathrm{BSMMU}$, Dissertion FCPS examination ,Dhaka,2005.

7. Khatoon RA. Clinical profile of the patient admitted with hydatidiform mole in $\mathrm{DMCH}$, Dhaka-A study of eighty cases. Dissertation FCPS examination, Dhaka1995. 
8. Akter. Hydatidiform mole. Dissertation ,FCPS examination, Dhaka 1981

9. Mungan T, Kuscu E, Dabakoglu T, Seroz S, Ugur M, Cabanoglu O,Hydatidiform mole; clinical analysis of 310 patients. International journal of Obstel Gynaecol, 1996;25;233-238

10. Reddy $T$, Rajeshwari K, Epidemiology of gestational trophoblastic disease in Govt. Maternity hospital Tirupati,J. Obset Gynecology of India 1994;p565-569.

11. Martin $\mathrm{BH}, \mathrm{Kim} \mathrm{JH}$. Changing face of gestational, trophoblastic tumor. Int J Obstel. Gynaecol ,1998;(60):111-120

12. Matsui H, litsuka $Y$, Yamazawa K, Tanaka $\mathrm{N}$, Seki K, Sekiya S, Changes in the incidence of molar pregnancies. Hum. Reprod. 2003 Jan;18(1):172-5.
13. Goldstein DP, BerkowitzRS. Current management of complete and partial molar pregnancy. J Reprod Med 1994;39(3);139-146.

14. Curry SL et al. Hydatidiform mole-Diagnosis, management and long term follow up of 347 patients.J Obstel Gynaecol 1984;27 (1):192-198.

15. Mangili G, Garavaglia E, Cavoretto P, Gentile C, and Scarfone G, Rabaiotti E. Clinical presentation of hydatidiform mole in northern Italy: has it changed in the last 20 years? Am J Obstel Gynecol.2008 Mar;198(3):302.

16. Soto Wright V. Bernstein M, Goldstein DP, Berkowitz RS. The changing clinical presentation of complete molar pregnancy.Obset Gynaecol 1995;264(5):775-779.

17. Gemer O, Sega S, Kopman A, Sasson E. The current clinical presentation of complete molar pregnancy. Arch Obstel Gynaecol, 2000;264(1):33-34. 